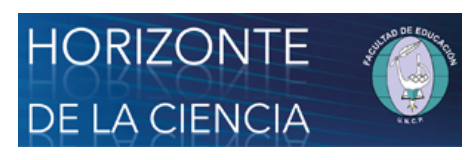

Horizonte de la Ciencia ISSN: 2413-936X

horizontedelaciencia@uncp.edu.pe

Universidad Nacional del Centro del Perú

Perú

\title{
Freud x Lacan: ¿Dualidad o complementariedad en el estudio de la angustia?
}

\author{
Pucci Medina, Sônia Grácia \\ Freud x Lacan: ¿Dualidad o complementariedad en el estudio de la angustia? \\ Horizonte de la Ciencia, vol. 10, núm. 18, 2020 \\ Universidad Nacional del Centro del Perú, Perú \\ DOI: https://doi.org/10.26490/uncp.horizonteciencia.2020.18.396
}

Los autores otorgan el permiso a compartir y usar su trabajo manteniendo la autoría del mismo. Atribución no comercial (CC BY-NC) 4.0 


\title{
Freud x Lacan: ¿Dualidad o complementariedad en el estudio de la angustia?
}

\author{
Freud x Lacan: Duality or complementarity in the anguish study? \\ Freud x Lacan: Dualidade ou complementaridade no estudo da angústia? \\ Feud x Lacan: ¿Llakikutyay yachayćhu ishkaytay icha yapaykuna? \\ APITEYETATSIRI IYOTANETANTSI AÑANABENTERO KARIPEROTATSIRI AYOTANE \\ Freud x Lacan: pitetagantsi kengagantsi kara okantokotagani ora nibasëretokotagantsi?
}

Sônia Grácia Pucci Medina Datos de la autora

DOI: https://doi.org/10.26490/

Associação Psicanalítica do Município do Rio de Janeiro,

Brasil

uncp.horizonteciencia.2020.18.396

sgpmedina2008@gmail.com

(9) http://buscatextual.cnpq.br/buscatextual/

Recepción: 10 Junio 2019

visualizacv.do $\mathrm{id}=950.900 .490 .496 .4658$

Aprobación: 21 Octubre 2019

Recepción: 10 Junio 2019

Aprobación: 21 Octubre 2019

\section{Resumen:}

El objeto de estudio de este trabajo es la compilación de la teoría del concepto de angustia desarrollada por Freud en sus relaciones con el concepto de represión. A lo largo de su trabajo, hay dos teorías y varias elaboraciones sobre la angustia. Freud, después de 1925/6, a menudo se refiere a sus dos teorías, aunque en cierta medida las teorías se superponen y entrelazan. Hasta 1925/6, el término angustia se entiende como el efecto de estímulos represados excesivos debido a la satisfacción de no conducir. El sujeto impedido de descargar la libido sexual, por la acumulación de excitaciones, los convierte en síntomas de miedo, causando sudoración, taquicardia, contracciones musculares, entre otros. Las circunstancias externas concretas o la maduración insuficiente impiden que el sujeto satisfaga libremente sus impulsos de impulso y produzca estados de angustia. La idea de Freud es antigua cuando escribe sus cartas a Breuer y compila en "El mecanismo psíquico de los fenómenos histéricos" (1996, p. 41) sobre el mecanismo psíquico de los fenómenos histéricos: "que se experimentan estímulos excesivos por el tema como algo abrumador que lo lleva a un estado de miedo e impotencia ". De esta manera, la represión finalmente produce las diversas formas de neurosis de ansiedad. Al reformular su teoría de la angustia, Freud mantiene la idea de que el sujeto expuesto a una excitación excesiva vive en una situación de impotencia, necesitando lidiar con los estímulos que lo afectan frente a una amenaza de datos real o imaginaria. Desarrolla la teoría del segundo tema, sitúa a la UE como un lugar de miedo y presenta otra concepción de la relación entre represión y angustia, invierte la secuencia previa de represión producida por la angustia y afirma que será la angustia hacia la que la UE siente el peligro, que llevará al sujeto a la represión. Básicamente, temores como el miedo a la castración o el miedo a la pérdida del amor materno llevarán al sujeto a reprimir sus tendencias libidinales.

Palabras ClaVE: Objeto, angustia, ansiedad, represión, likana, llakikutyay, munapakyay, kutilimapay, Ayotakotantyariri, kariperotatsiri, kinkitsashiriantsi, tsarobimotakainerine kiteiteripaye, Antagero, araganeintagantsi, kengagantsienga, kenganijintagantsi.

\section{Abstract:}

The object of study of this work is the compilation of the theory of the concept of anguish developed by Freud in its relations with the concept of repression. Throughout his work, there are two theories and several elaborations about anguish. Freud after $1925 / 6$ often refers to his two theories, although to some extent theories overlap and intertwine. Until 1925/6 the term anguish is understood as the effect of excessive dammed stimuli due to non-drive satisfaction. The subject prevented from discharging

\section{NotAS DE AUTOR}

Datos deSônia Grácia Pucci Medina. Investigador y docente de psicoanálise, psicologia laboral y educación. Doctor en Psicologia Social por la Universidad la autoraJohn Kennedy, Buenos Aires, Argentina. Magister en Teoría Psicoanalítica por la Pontificia Universidad Católica del Rio de Janeiro.

sgpmedina2008@gmail.com 
the sexual libido, over the accumulation of arousals, turns them into symptoms of fear, causing sweating, tachycardia, muscle contractions, among others. Concrete external circumstances or insufficient maturation prevent the subject from freely satisfying his drive urges and produce distress states. Freud's idea is old when he writes his letters to Breuer, and compiles in "The Psychic Mechanism of Hysterical Phenomena" (1996, p. 41) on the Psychic Mechanism of Hysterical Phenomena: "that excess stimuli are experienced by the subject as something overwhelming that leads him to a state of fear and helplessness". In this way, repression eventually produces the various forms of anxiety neurosis. By reformulating his theory of anguish, Freud maintains the idea that the subject exposed to excessive arousal lives in a situation of helplessness, needing to deal with the swirling stimuli that affect him in the face of real or imaginary threat of data. It develops the Theory of the Second Topic, and situates the EU as a place of fear and presents another conception of the relationship between repression and anguish, reverses the previous sequence of repression produced by anguish and states that it will be the anguish that the EU feels towards the danger, which will lead the subject to repression. Basically, fears such as the fear of castration or the fear of loss of maternal love will lead the subject to repress his libidinal tendencies.

KEYWORDS: Object, anguish, anxiety, repression.

\section{Resumo:}

O objeto de estudo deste trabalho é a compilação da teoria do conceito de angústia desenvolvida por Freud em suas relações com o conceito de repressão. Ao longo de seu trabalho há duas teorias e várias elaborações sobre a angústia. Freud, depois de $1925 / 6$ se refere com frequência as suas duas teorias, embora até certo ponto as teorias se superponham e entrelacem. Até $1925 / 6$ o termo angústia é entendido como o efeito de excesso de estímulos represados devido à satisfação de não conduzir. O sujeito impedido de descarregar a libido sexual, pela acumulação de excitações, os transforma em sintomas de medo, causando sudoração, taquicardia, contrações musculares, entre outros. As circunstâncias externas concretas ou a maturação insuficiente impedem que o sujeito satisfaça livremente seus impulsos de impulso e produza estados de angústia. A ideia de Freud é antiga quando escreve suas cartas para Breuer, e compila em "O mecanismo psíquico dos fenômenos histéricos” (1996, p. 41), sobre o mecanismo psíquico dos fenômenos histéricos: "que se experimentam estímulos excessivos pelo tema como algo avassalador que o leva a um estado de medo e impotência". Desta forma, a repressão finalmente produz as várias formas da neurose de ansiedade. Ao reformular sua teoria sobre a angústia, Freud mantém a ideia de que o sujeito exposto ao excesso de excitação vive uma situação de impotência, necessitando lidar com os estímulos que o afetam, perante uma ameaça real ou imaginária de dados. Desenvolve a teoria do segundo tema, situa à UE como um lugar do medo e apresenta outra concepção da relação entre repressão e angústia inverte-se a sequência anterior de repressão produzido pela angústia e afirma que será a angústia que o EU sente perante o perigo, que levará o sujeito à repressão. Basicamente, temores tais como o temor à castração ou o medo da perda do amor materno levarão ao sujeito reprimir suas tendências libidinais.

Palavras-CHAVE: Objeto, angústia, ansiedade, repressão.

\section{INTRODUÇÃO}

Nosso objeto de estudo é situar e discutir as definições e o status da noção de objeto na teoria psicanalítica de Freud e a relação objetal com a angústia lacaniana, com o interesse de observar socialmente a criança e seus transtornos.

Diante do problema: o estresse desenvolve a neurose da angústia, ou a relação do objeto com a angústia, favorece uma continuidade ou ruptura?

O artigo, tem como objetivo projetar a articulação entre sujeito e objeto e relacionar os conceitos de angústia e repressão. Questionando a hipótese de que o sujeito e o objeto são a concepção de angústia que se apresenta, na psicanálise, intimamente ligada à função do objeto?

Embora a angústia seja o sinal afetivo que designa a incidência do objeto que causa o desejo, a angústia e o desejo não se confundem. O desejo é causado pela função do objeto, através de uma perda, a cada vez que a angústia é atravessada.

A ansiedade está no tempo antes do desejo. É no ato chamado por Lacan de "atribuição do objeto" que os objetos parciais da pulsão assumem a função de causa do desejo. Uma vez localizado o momento de angústia, quando o objeto é perdido pelo ato de atribuição, o que ocorre, por ser irredutível à linguagem, permite a constituição do sujeito como desejante. 
Tomando como metodologia de pesquisa, uma revisão bibliográfica da obra freudiana sobre os processos de sexualidade, inibição e castração e os estudos do Seminário de Lacan 4.

\section{DESENVOLVIMIENTO}

O fato é que a noção de objeto não apenas evoluiu, mas sofreu uma mudança mais do que significativa de Freud para o momento presente da teoria psicanalítica, segundo Uyratan de Carvalho em Introdução à Psicanálise (2002, p. 38).

E há uma dificuldade essencial na definição do objeto da psicanálise. Essa dificuldade resulta da própria natureza desse objeto. Falar de objeto na psicanálise é quase paradoxal, pois não apresenta nenhuma objetividade, como acontece com os objetos das ciências positivas, como a química, a física etc. Greenberg e Mitchell (1994, p.137), concluem, que mesmo sendo o objeto experimentado apenas pela subjetividade de um sujeito em análise, também não se pode qualificá-lo como subjetivo.

Este objeto tem como suporte apenas a palavra que é professada em uma análise. A partir dessa observação, pode-se deduzir que ele é simbólico, pois depende da estrutura simbólica que é própria da linguagem. No entanto, para Lacan no Seminário 4 (1995, p. 204), esse objeto é real e não apenas simbólico ou imaginária, como se poderia supor com base no fato de que podemos deduzir a partir da versão imaginária de fantasia inconsciente e a sua transposição simbólica na linguagem falada.

Freud introduziu a noção de objeto de um de seus conceitos fundamentais, o conceito de unidade, que ele tinha uma base muito real, isto é, uma fonte de excitação localizada nos principais orifícios do corpo (boca e ânus), de acordo com Uyratan de Carvalho (2002, p.79).

Entre os quatro elementos que, segundo Freud, constituem a pulsão, o objeto seria apenas o componente mais contingente, variável e, sobretudo, substituível. Essas características diferenciam-no do objeto biológico do instinto, que é fixo e hereditário, fazendo parte de uma montagem orgânica da qual depende a sobrevivência do indivíduo. Agora, o objeto da pulsão não é organicamente predeterminado, mas de uma maneira que é construído através das experiências de satisfação, trauma e as vicissitudes através do qual a criança nos primeiros anos de vida.

Uma das características mais paradoxais desse objeto, no entanto, é que Freud o define desde o início de sua trajetória como um objeto perdido. Mais tarde, por exemplo, em seu artigo sobre a negação, Freud define a relação sui generis que o objeto tem com o real. Neste artigo, ele define o princípio da realidade como uma função psíquica que permite ao sujeito buscar na realidade por um objeto perdido. Acompanhando Freud através de Uyratan de Carvalho (2002, p. 60), o traço mnésico deixado no inconsciente pela experiência de satisfação, o sujeito alucina o objeto tal como existe na memória inconsciente.

Depois de Freud, foi a vez de Karl Abraham introduzir uma modificação fundamental na noção freudiana do objeto: a divisão do objeto em um objeto parcial e um objeto total. Essa dualidade do objeto vai ter algumas consequências de importância primordial para a teoria e prática da psicanálise. David Zimerman (2010, p. 368), destaca a concepção kleiniana do objeto, que definiu duas posições-chave do desenvolvimento psíquico, dependendo do objeto em questão sobre a relação entre o sujeito e o outro: a posição esquizo-paranóide sobre objetos parciais (bom e mau, mama, fezes, pênis bom ou ruim no corpo materno, etc.) e a posição depressiva, correlativa da constituição de um objeto total (pai e mãe boa ou ruim, etc.).

Outro autor contemporâneo, segundo David Zimerman (2010, p. 447), que muito contribuiu para revolucionar nossa concepção atual do objeto da psicanálise, foi Winnicott. A sua invenção de objeto de transição foi o ponto de partida para uma nova posição de tiro do analista para o tratamento, graças à concepção criacionista do objeto, em que o analista executa uma função de agente ativo e partilhar com a análise de um campo para ser descoberto e produzido por ambos. Esse campo, também chamado de transição, implica que o objeto não é um dado, mas uma descoberta do tratamento analítico. 
Nos anos cinquenta, houve uma preponderância no movimento psicanalítico internacional da noção de relação de objeto, que, tomando-se certas noções de Karl Abraham, era um quadro evolucionista e regulamentar a atividade psicanalítica.

A formação sujeito psíquico é então concebida como uma sucessão de passos que levam ao indivíduo, relação de fase mais antigo com objetos parciais, para uma maturidade psicossexual, representado pela relação heterossexual a um objeto, definido em termos de amor genital.

Uma concepção psicanalítica dessa ordem implica um desvio significativo da ética da psicanálise. $\mathrm{O}$ tratamento psicanalítico é assim subordinado às normas sociais e até à moralidade coletiva, que acredita que o propósito da psicanálise consiste libertando o indivíduo dos traços infantis da sexualidade, segundo relatos de Uyratan de Carvalho (2002, p. 184).

Para Freud em A pulsão e seus destinos (1996, p. 198):

a divisão do sujeito entre os restos de sua sexualidade infantil e o que se chama vida adulta é algo irredutível, porque a sexualidade do adulto é condicionada pelo desejo infantil, indestrutível por definição.

Mas a divisão mais radical da relação do sujeito com o sexo é, segundo Freud, a necessidade que o obriga a obedecer a uma dupla lógica da sexualidade: uma primeira lógica corresponde à fase pré-genital da sexualidade; uma segunda lógica, que começa com a fase genital, e que é expressa em termos fálicos e traduz em significado fálico os objetos parciais do primeiro estágio da vida sexual do indivíduo.

Essa concepção freudiana (1972) é claramente estabelecida em um artigo de 1923 intitulado The Genital / Infant Organization. Em outro artigo 1917 (Nas transposições de libido, mais particularmente erotismo anal), Freud deixa, no entanto, definir uma certa ambiguidade em sua definição lógica, quando ele diz que a possibilidade de uma equivalência entre objetos parciais e $($ excrementos $=$ dinheiro $=$ presente $=$ bebê $=$ pênis). Mas sua conclusão deste artigo de 1923 sobre a fase fálica é inequívoca.

Eles parecem momentos capitais do processo psicanalítico de Lacan. Não é apenas sobre a introdução de uma discussão evolucionista, mas epistemológica do conhecimento analítico, mas o próprio Lacan, na relação objeto, em algum momento ele falou da "evolução histórica da psicanálise", como ele se referiu a sua teoria e sua pratica.

De qualquer forma, parece que essa questão não é absolutamente extemporânea, não apenas porque a psicanálise traz novas contribuições sobre conhecimento e ciência, mas principalmente no que se refere ao trabalho analítico - ou, devo dizer, um ato analítico? Como se pode inferir que tanto na teoria quanto na prática há uma disjunção - para dizer o mínimo - entre um seminário e outro.

No seminário 4, Lacan (1995, p. 279), faz uma crítica da relação de objeto que dá prevalência, na teoria analítica, à relação do objeto como primário, fundando progresso analítico numa retificação da relação entre sujeito e objeto.

Este objeto-modelo, se fundamenta na prática analítica do imaginário e na relação dual, independentemente dos ensinamentos de Freud, quando marcou que este sempre foi o objeto perdido, em psicanálise da falta, como dinamicamente criativa, e que o objeto seja sempre redescoberto (wiederfindung), que nunca seja o objeto original, portanto insatisfatório, e o objeto genital, harmonioso, não é mais que um objeto idealizado.

$\mathrm{Na}$ relação objetal, Lacan, seguindo de perto Freud, apresenta-nos um mundo significativo, ou seja, tudo é elevado à dignidade do significante, até o corpo só pode ser abordado pelo significante. E, quando se diz significativo, é o significante fálico.

De acordo com Lacan, no Seminário 4 (1995, p. 115):

..aqui estamos no campo dos objetos especulativos; da mitologia edípica; da castração como uma punição operada por um $\mathrm{O}$; do desejo e da lei; do amor como um presente simbólico, isto é, como o objeto de satisfação se torna um objeto de presente; do objeto de desejo, objetos fascinantes; do amor como caminho privilegiado de acesso ao objeto do desejo (o caminho do amor dá acesso ao objeto simbólico, o falo, como símbolo do desejo da mãe, de desejar como desejo do eu). 
Isso implica, na prática, responder à hipótese "o que isso significa?" Isto é, o sintoma, o sonho, o lapso tem um significado a ser decifrado.

Lacan apresenta um objeto que se mostrará irredutível ao significante, objeto heterogêneo que escapa ao campo semântico e incomensurável; portanto, podemos dizer, um objeto que ele designa algebricamente com o diminutivo a.

A clínica do real se impôs. Desejo como descanso, devido à necessidade e demanda, foi um descanso significante aberta à dialética, e não percebeu a libido, ele aparecerá como algo muito diferente de um outro significativo, ele aparecerá como um órgão que não se oponha à dialética. É o pedaço de corpo, é o "quilo de carne". Não é um desejo, mas um prazer de descanso. O prazer como uma função impossível de negativizar.

A angústia parte de um termo também obscuro e mítico, que não é o desejo da mãe, mas a alegria. A angústia diferente do desejo é o que não engana, é o que não é permitido significar, é, então, o real. Este verdadeiro descanso é o gozo, na medida em que não se deixa capturar pelo significante, o gozo irredutível ao princípio do prazer.

Estas são as novas coordenadas que iniciam a revisão dos postulados freudianos clássicos, bem como os primeiros ensinamentos de Lacan. Do lado de Freud, o questionamento da castração (e do mito edípico) como o principal postulado da psicanálise. Do lado de Lacan, a degradação de desejo e significante, assim como a metáfora paterna e o fracasso do nome do Pai. Aqui vai a subordinação do simbólico tão real, não uma singularidade do nome do Pai; o caminho da ansiedade leva ao objeto real, aponta para levar o objeto de satisfação, uma satisfação que não é por necessidade, mas por instinto, uma satisfação que é prazer.

Em Freud, a angústia se une à perda do objeto; em Lacan surge quando a falta significa um objeto.

A consequência clínica é a mudança de questão agora, não "O que isso significa", mas "o que satisfaz?" A primeira interpretação a que se refere o significante, o segundo refere-se a causa de desejo, o objeto como a causa de desejo.

Para Sigmund Freud, (1933[1932] /1996, p.85):

Trata-se efetivamente de concepções, isto e, de trazer a luz as representações abstratas corretas, e de aplicálas a matéria bruta da observação, que permitirá fazer com que delas saiam a ordem e a transparência.

É com essas palavras que Sigmund Freud abre a trigésima segunda das novas conferências introdutórias a psicanálise, anunciando que irá falar de angustia e vida pulsional. E há um motivo especial para ele utilizar o termo "concepção". É preciso conceber, produzir uma maneira de se tratar a angustia, já que, segundo Freud, ela aponta para o que não se revela abertamente na experiência nem em representações que tentem abrange-la.

Enquanto encontrava-me no aposento ao lado, ouvi uma criança, com medo do escuro, dizer em voz alta: 'Mas fala comigo, titia. Estou com medo!' 'Por quê? De que adianta isso? Tu nem estas me vendo.' A isto a criança respondeu: 'Se alguém fala, fica mais claro'”, Sigmund Freud, (1917 [1916-17] /1996, p. 408).

A angustia se insere na obra de Freud da mesma forma que o pensamento nela encontra-se orientado: por um caminho que avança através de recuos, abandono de concepções, retificações e cortes com relação a tudo aquilo que outrora foi sustentado.

Não se encontra em Freud apenas um encaminhamento ao estudo do problema da angustia, nem ela chega a ser definida em um só golpe. Apenas pode se considerar a função do termo angústia na psicanálise ao tomálo por suas reformulações e pelos sucessivos cortes que sobrevieram pontualmente em sua direção.

Desde o início de suas pesquisas no campo da neurose, Freud já apontava que os sintomas da neurastenia (a saber, pressão intracraniana, propensão a fadiga, irritação espinhal e dispepsia com flatulência e constipação, (Freud, 1895 [1894] /1996, p. 93 e 1898/1996, p. 255]) baseavam-se em fatores sexuais da vida dos sujeitos (Freud, 1893a/1996, p. 223). Segundo ele, os neurastênicos são sujeitos com vida sexual empobrecida por alta frequência de emissões de produtos sexuais, por exemplo, pela masturbação (Freud, 1898/1996, p. 255).

Depois de mostrar que essa afecção está intimamente ligada à sexualidade dos sujeitos, Freud se incumbe da tarefa de distingui-la da neurose de angustia e também pela via sexual que o faz, descartando a ideia de que a neurose de angustia seria um prolongamento da angustia que pode surgir na relação sexual (por 
questões psíquicas que afligiriam os sujeitos), Freud diz que de modo algum ela é "continuada, relembrada, histérica" (Freud, 1950 [1894]/1996, p. 235), sendo, ao contrário, proveniente de uma excitação sexual que permanece no registro somático, físico.

No primeiro tempo da angustia na obra de Freud, enquanto a neurastenia está ligada a um "empobrecimento da excitação" sexual, a neurose de angustia se define por um "acumulo de excitação" que acomete o sujeito (Freud, 1895 [1894]/1996, p. 114-15), de maneira a se tratar "de uma questão de acumulação física de excitação —isto é, uma acumulação de tensão sexual física” (Freud, 1950 [1894]/1996, p. 237). Porém, a angustia não pode ser simplesmente localizada no acumulo da excitação, é preciso que haja a transformação do acumulo de tensão sexual em angustia.

A concepção da angustia surgindo a partir da transformação do acumulo de tensão sexual é uma posição que Freud sustenta durante muito tempo, só a abandonando em 1925, no texto Inibição, sintoma e angústia (1926 [1925] /1996).

Em Além do princípio do prazer (1920/1996) sob o nome de "princípio de constância", Freud associa a neurose de angustia principalmente ao coito interrompido em razão desta prática envolver uma estimulação física completamente incapaz de produzir uma descarga que seja adequada ou suficiente.

Todas essas indicações - de que estamos diante de um acumulo de excitação; de que a angustia, provavelmente correspondente a essa excitação acumulada, e de origem somática, de modo que o que se está acumulando é uma excitação somática; e ainda, de que essa excitação somática e de natureza sexual é acompanhada por um decréscimo da participação psíquica nos processos sexuais, todas essas indicações, levam-nos a esperar que o mecanismo da neurose de angustia deva ser buscado numa deflexão (desvio) da excitação sexual somática da esfera psíquica e no consequente emprego anormal dessa excitação. (Freud, 1895 [1894] /1996, p. 108-09).

$\mathrm{Na}$ Interpretação dos Sonhos, (Freud 1900/1996, p. 167), com a tarefa de elucidar porque o sonho é a realização de um desejo, Freud se pergunta muitas vezes, ao longo da Interpretação, como alguns sonhos podem chegar a surtir uma sensação de pesar ou desprazer enquanto ocorrem, ou seja, "como podem os sonhos aflitivos e os sonhos de angustia ser realizações de desejos"? (Freud 1900/1996, p. 170).

Frente a essa questão, Freud opera uma disjunção entre aquilo que é o conteúdo manifesto dos sonhos e o que neles se afirmam de maneira latente, uma vez que o conteúdo manifesto pode ser aflitivo e, ao mesmo tempo, ocultar a realização de um desejo afigurado como latente. O que Freud conclui daí é que há uma censura que atua nos sonhos como uma defesa contra a realização do desejo e que a realização onírica desse desejo só pode ser efetuada ao sofrer uma serie de distorções em seu sentido (Freud, 1900/1996, p. 176).

Para dar sustentação ao desejo que se imiscui no material do sonho, apesar da censura investida contra ele, Freud sugere que a realização do trabalho da elaboração onírica ocorre tanto através de uma instancia responsável por expressar o desejo no sonho, como por outra que, ao exercer uma censura sobre esse desejo, promove a distorção de seu material.

\section{UM SonHo}

Um exemplo, retirado da Interpretação, pode auxiliar a esclarecer tais asserções: Um homem, conhecido de Freud, contou-lhe um sonho para, a princípio, contradizer sua teoria de que os sonhos são realizações de desejo. Dizia ele:

sonhei (...) que chegava a minha casa de braço dado com uma senhora. Havia uma carruagem fechada em frente à casa e um homem dirigiu-se a mim, mostrou-me suas credenciais de policial e me solicitou que o acompanhasse. Pedi-lhe que me concedesse algum tempo para pôr meus negócios em ordem (Freud, 1900/1996, p.188).

Indagado por Freud sobre o motivo pelo qual foi dada a ordem de prisão no sonho, o homem disse que se tratava de "infanticídio". Depois de uma certa resistência, esse sujeito começa a contar a Freud que ele 
tivera o sonho logo de manhã, depois de mais uma vez ter mantido relações sexuais com uma moca casada que havia levado à sua casa na noite anterior e de quem era amante. Além do mais, ele relatou a Freud que teve o cuidado de realizar o coito interrompido a noite toda com tal senhorita, para que uma gravidez não viesse a tornar público aquele relacionamento. Freud afirma que o desagradável sonho de estar sendo preso era uma realização de desejo, na medida em que, assim, o homem se tranquilizava com a ideia de que não havia risco de, naquelas relações sexuais, uma criança ter sido concebida, "ou, o que dá no mesmo, que matara uma criança" (Freud 1900/1996, p. 189).

Os sonhos de angustia, segundo Freud, se incluem como uma subespécie dos sonhos de conteúdo aflitivo (Freud, 1900/1996, p. 194), de maneira que já é possível vislumbrar uma modificação de sua posição em relação ao modo como a angustia foi concebida nos tempos do artigo da neurose de angustia, em 1894 . No sonho acima descrito, o desprazer que surgiu em relação ao conteúdo onírico acarreta possibilidade de se considerar a angustia, na Interpretação, não em função de uma cota de energia física retida no corpo, mas como uma forma de defesa em relação ao desejo, uma maneira de preservá-lo sob o recalque.

\section{Conclusão}

Apesar destas diferentes acepções, podemos considerar que na teoria freudiana, de uma forma geral, o objeto está sempre ligado ao processo da história de vida do sujeito, ou seja, se o objeto é determinado por algo, não o é simplesmente por elementos constitucionais de cada sujeito, mas sim pela história de vida (fundamentalmente a história de vida infantil).

Neste sentido, mesmo a assim chamada "escolha de objeto" presente na adolescência e na vida adulta, se não ocorre por acaso, também não pode ser concebida como completamente determinada, seja constitucionalmente, seja por uma decisão soberana da consciência ou do ego.

Esta mesma concepção nos parece adequada para pensar, em um primeiro nível, o estatuto do objeto na teoria freudiana. Freud se refere a objeto tanto no sentido de um objeto dito "externo" quanto a um objeto dito "interno". O objeto é simultaneamente interno e externo. Trata-se de entender as formulações freudianas para além das tentativas de reduzi-las quer ao empirismo quer ao idealismo. Assim, seria preciso reconhecer que Freud supõe um sujeito (pulsional) constituindo objetos e objetos (de identificação) constituindo o sujeito.

A partir da trajetória realizada, é possível propor uma concepção freudiana do sujeito, apesar dos riscos envolvidos. Entendo que o sujeito precisaria ser pensado como resultado, simultaneamente, da complexa intensidade dos movimentos pulsionais e das sucessivas identificações (possíveis também graças a uma presença "ativa" de objetos como a mãe, o pai etc.) ocorridos em seu processo constitutivo.

A ideia de simultaneidade é aqui fundamental. Não penso que haja anterioridade das pulsões com relação aos objetos de identificação, como tampouco me parece possível dizer que os objetos antecedam os movimentos pulsionais.

Seria necessário reconhecer em Freud uma lógica não identitária, uma lógica da suplementaridade para dar a essa concepção sua formulação mais rigorosa. Os polos da dualidade (pulsão-identificação, interno-externo, psíquico-empírico ou mesmo sujeito-objeto) não precisam ser pensados como cada um sendo idêntico a si mesmo. Tampouco bastaria pensar os polos como complementares, o que ainda manteria certa unidade permanente e definitiva na concepção de cada um dos elementos complementares, ou então a diluição de cada polo em um novo "produto" resultante da complementaridade.

\section{ReFERENCIAS BIBLIOGRÁfiCAS}

Carvalho, Uyratan. (2002). Introdução Psicanálise I. 4ª . Ed. Reproarte Ed. Rio de Janeiro - RJ 
Freud, S. Studienausgabe, Frankfurt, S. Fischer VerIag, (1972). Drei Abbandlungen zur Sexualtheorie, 1905, v. 5, p. 37-147. Über einen besonderen Tvpus der objektwahl beim Manne, (1910), v. 5, p.185-195. Eine Kindheitserinnerung des Leonardo da Vinci, (1910), v. 10, p. 88-159. Zur Einführung des Narzissmus, (1914), v. 3, p.37-68. Das Unbewusste, (1915), v. 3, p.119-174. Trauer wtd Melancholie, (1917), v. 3, p. 183-212. Das Ich und das Es, (1923), v. 3, p. 273-330. Fetichismus, (1927), v. 3, p. 379-388.

Freud, S. e Breuer, J. (1996). Sobre o mecanismo psíquico dos fenômenos histéricos: Comunicação Preliminar, (1895). Estudos sobre histeria em Standard Brasileira das Obras Psicológicas Completas de Sigmund Freud. Rio de Janeiro: Imago.

Greenberg \& Mitchell. (1994). Relacões Objetais na Teoria Psicanalítica. Porto Alegre. Artes Médicas.

Lacan, J. (1995). Seminário 4: a relação de objeto. Rio de Janeiro: Zahar. [Trabalho original publicado em 1956].

Zimerman, E. (2010). Fundamentos Psicanalíticos. Teoria, técnica e clínica. Porto Alegre. Artmed.

Los autores otorgan el permiso a compartir y usar su trabajo manteniendo la autoría del mismo. CC BY-NC 